\title{
Status Sociométrico e Avaliação de Características Comportamentais: Um Estudo de Competência Social em Pré-Escolares
}

\author{
Maria de Lima Salum e Morais \\ Emma Otta ${ }^{12}$ \\ Cristiana Tieppo Scala \\ Universidade de São Paulo
}

\begin{abstract}
Resumo
Neste estudo, investigaram-se correlatos entre escolhas sociométricas positivas e negativas e atribuição de características comportamentais por parte de companheiros de uma classe de pré-escola. Testou-se a adequação de um instrumento elaborado com essa finalidade para a aplicação em crianças de cinco anos de idade, empregando-se figuras ilustrativas com os propósitos de facilitar a compreensão da tarefa e de motivar os participantes a se manterem interessados durante a prova. As características comportamentais pesquisadas foram, na esfera social: aceitação/isolamento social, participação/não-participação nas atividades, dependência/independência da professora e dominância/ submissão; e na esfera afetiva, tristeza/alegria e medo/coragem. O instrumento mostrou-se adequado para avaliação desses atributos em pré-escolares. Verificou-se que as crianças foram capazes de discriminar a maior parte das características dos colegas, associando escolhas positivas a atributos social e afetivamente positivos. Foram constatadas diferenças de gênero: os meninos foram mais avaliados por características sociais e as meninas por atributos afetivos.

Palavras-chave: Competência social; status sociométrico; preferência por companheiros; avaliação de características comportamentais; características sociais e afetivas.
\end{abstract}

\section{Sociometric Status and Peers' Behavioral Descriptions: A Study of Preschoolers' Social Competence}

\begin{abstract}
This study examined the correlations between sociometric choices and preschool peers' behavioral descriptions. The appropriateness of an instrument created for the evaluation of behavioral attributes for five years old was tested, using illustrative cards to motivate participants during the task. Behavioral social characteristics evaluated were: social acceptance/ withdrawal, participation/lack of participation in schoolwork, dependence/independence from teacher and dominance/ submission. Affective characteristics investigated were happiness/sadness and fear/courage. The instrument was adequate to its goals. The children were able of adequately discriminate most of the behavioral characteristics, attributing prosocial and positive affective characteristics to preferred peers and antisocial and negative affective descriptions to rejected peers. Gender differences were found: boys were evaluated by social characteristics whereas girls were evaluated by affective characteristics. Keywords: Social competence; sociometric status; preference by peers; evaluation of behavioral characteristics; social and affective characteristics.
\end{abstract}

Competência social é um conceito usado para designar a capacidade de interação e de adaptação da criança ao grupo de companheiros (Attili, 1990). A investigação dessa capacidade na criança tem contribuído para o entendimento de sua importância no desenvolvimento psicossocial. Nas relações que a criança estabelece com o grupo de companheiros estão em jogo habilidades essenciais - como revezamento de papéis e adoção da

\footnotetext{
${ }^{1}$ Endereço para correspondência: Departamento de Psicologia Experimental do Instituto de Psicologia da USP, Av. Prof. Mello Moraes, 1721, 05508-900, São Paulo, SP. Fone: (11) 3818-4448. Fax (11) 3818-4909. E-mail:emmaotta@usp.br

${ }^{2}$ Esta pesquisa foi subvencionada pelo CNPq. Agradecemos à Profa. Vera Silvia Raad Bussab, do Depto. de Psicologia Experimental da USP, pelas importantes contribuições para a discussão deste trabalho e às crianças e professoras que colaboraram com sua participação neste estudo.
}

perspectiva do outro, nos domínios afetivo e cognitivo - e a possibilidade de experimentação do poder da criança no grupo, de estratégias para exercer esse poder, assim como o exercício de mecanismos para obter aceitação e para manter sua posição no grupo. Tais questões são importantes tanto para a resolução de problemas atuais da criança - como a solução de tarefas que enfrenta no curso de seu desenvolvimento e a avaliação de pessoas que possam servir-lhe como referentes para o apoio social -, quanto para o desenvolvimento de capacidades necessárias para sua adaptação social futura.

Dentre as dimensões utilizadas para investigar como a criança se insere no grupo de companheiros, encontramse a popularidade e a aceitação social, que podem ser medidas através de técnicas sociométricas de escolha. A combinação entre medidas de aceitação e de rejeição 
social gera o status sociométrico do indivíduo no grupo. Num trabalho que trouxe contribuições fundamentais para a área, Coie, Dodge e Coppotelli (1982) propõem duas medidas - preferência social e impacto social derivadas de respostas das crianças a duas questões simples: "de que colega(s) você gosta mais?" e "de que colega(s) você gosta menos"? Com base nas repostas a essas perguntas, os autores classificaram as crianças como: populares - com alto índice de aceitação e baixo de rejeição; rejeitadas - com alto índice de rejeição e baixo de aceitação; negligenciadas - com índices baixos ou nulos de escolha positiva e negativa; intermediárias - com índices moderados de escolha positiva ou negativa; e controversas - com altos índices de escolha positiva e negativa. Coie e colaboradores enfatizam a importância de se usarem escolhas sociométricas positivas e negativas para se obter um quadro mais diferenciado das dimensões envolvidas no estudo do status social. Apenas através da combinação dessas medidas é possível se chegar aos grupos de status sociais controverso e negligenciado.

Assim como o trabalho de Coie e colaboradores (1982), outros estudos têm apontado para o risco que sofrem as crianças rejeitadas, controversas e negligenciadas de desenvolverem problemas de ajustamento social atual e futuro (Attili,1990; Furnham, 1989; Hatzichristou \& Hopf, 1996; Parke e colaboradores, 1997; Rubin, 1990). Embora a maior parte dos trabalhos tenha sido dirigida para o acompanhamento de crianças rejeitadas, supomos que as negligenciadas, por serem praticamente ignoradas pelos colegas, também tenham um prognóstico desfavorável em seu desenvolvimento socioemocional. A respeito do prognóstico das crianças controversas, a quem são atribuídas características tanto positivas - como capacidade de liderança - , quanto negativas - como agressividade - cabem indagações: Serão elas consideradas como portadoras de risco de virem a apresentar comportamentos anti-sociais e de liderança conjuntamente, ou seja, de virem a tornar-se líderes de grupos marginais? Ou terão elas menos risco de desenvolverem condutas anti-sociais do que as crianças rejeitadas, pelo fato de terem características positivas que podem compensar as negativas? Por essas razões e pela tendência observada de as crianças apresentarem estabilidade de status sociométrico ao longo do tempo (Parke e colaboradores 1997), são importantes os programas de diagnóstico, intervenção e prevenção precoces. Quanto mais cedo forem detectadas dificuldades de ajustamento social, mais prontamente será possível interferir no sentido de evitar sua instalação de modo mais permanente e menos reversível. É preciso salientar, no entanto, que ainda restam muitas questões para serem investigadas através de pesquisas básicas, especialmente no que diz respeito às crianças controversas e negligenciadas.

Um modelo para a explicação das conseqüências da falta de competência social foi proposto por Furnham (1989). Parece se instalar um círculo vicioso difícil de ser quebrado sem ajuda externa (Figura 1). Déficits de competência social resultam em falta de amigos e em isolamento social, que podem despertar diferentes reações. Raiva é uma das emoções que pode ser despertada gerando ações agressivas, hostis e delinqüenciais. Autopiedade é outra reação possível, que pode resultar em depressão ou na busca de conforto através de

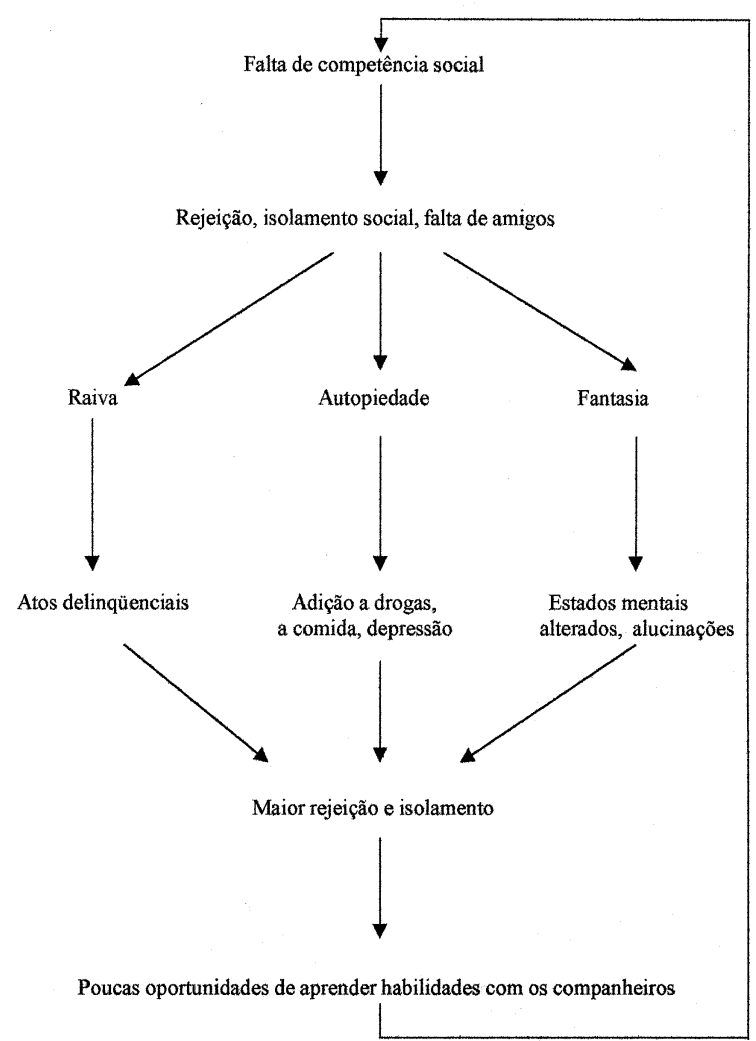

Figura 1. Um modelo das causas e conseqüências da falta de amigos (baseado em Furnham, 1989, p. 97)

diferentes formas de adição (comida, drogas). Se a saída encontrada para a falta de habilidade social for a exacerbação da fantasia, as conseqüências podem ser estados mentais alterados e alucinações.

O modelo de Furnham (1989) leva-nos a confirmar a importância do diagnóstico precoce. No entanto, a maior parte dos estudos sobre identificação de atributos comportamentais associados a status sociométrico tem sido realizada com crianças em idade escolar e com adolescentes. Coie e colaboradores (1982) estabeleceram 
relações entre status sociométrico e atributos comportamentais, conforme avaliação dos colegas, estudando alunos de três graus escolares, com, em média, nove, 11 e 14 anos de idade, utilizando-se de entrevistas. Hatzichristou e Hopf (1996) replicaram o estudo de Coie e colaboradores entrevistando crianças e adolescentes de 11 e 14 anos. Foi um de nossos propósitos no presente estudo adaptar e testar um instrumento de avaliação de características comportamentais para pré-escolares, com o intuito de se detectarem, mais precocemente, características comportamentais associadas aos diversos status sociométricos. Vários pesquisadores desenvolveram instrumentos auxiliares de entrevistas (figuras, bonecos, estórias, vinhetas) para a avaliação de diferentes funções em pré-escolares, para que as crianças, que se encontram num estágio de pensamento concreto, pudessem melhor compreender a situação ou o problema proposto. Encontramos estudos com tais características nas áreas de apego (Bretherton \& Ridgeway, 1990; Oppenheim, 1990), da teoria da mente (Leslie, 1991; Rosen, Schwebel \& Singer, 1997) e de auto-estima (Daniels, 1998; Harter \& Pike, 1984). Desconhecemos, porém, instrumentos semelhantes, específicos para avaliação da relação entre competência social e julgamento de atributos comportamentais por parte de companheiros na idade pré-escolar. Utilizamo-nos de figuras ilustrativas dos comportamentos pesquisados com a finalidade de facilitar a compreensão da tarefa e de motivar as crianças a participarem e a se manterem interessadas durante a prova.

Pesquisamos contrastes entre cinco atributos comportamentais relativos à esfera socioafetiva - ser dependente/independente da professora; ter muitos/ poucos amigos; dar/receber ordens; participar muito/ participar pouco das atividades; provocar/não provocar brigas - e duas características afetivo-emocionais mostrar-se alegre/triste; e mostrar-se corajoso/ medroso. A opção pelas características sociais empregadas neste estudo partiu do propósito de avaliar a associação entre comportamentos anti-sociais ou associais (provocar brigas, ter poucos amigos) e condutas pró-sociais (não brigar, ter muitos amigos) de um lado, e status sociométrico, de outro, com base em julgamentos dos companheiros de classe na pré-escola. Os primeiros atributos foram já constatados como preditivos de rejeição e os últimos, como correlatos de preferência social em outros estudos - por Attili (1990), com base num estudo observacional de pré-escolares e por Stormshak, Bierman, Bruschi, Dodge \& Coie (1999), com base na avaliação de professores de crianças mais velhas. A participação nas atividades foi estudada em relação a competência social por Vosk, Forehand, Parker e Rickard
(1982), que encontraram correlação positiva entre falta de participação e rejeição social em crianças em idade escolar. O item dependência da professora assemelha-se a "pedir ajuda", tópico incluído por Coie e colaboradores (1982), que constataram sua correlação com rejeição social em crianças mais velhas, pré-adolescentes e adolescentes.

Há relatos, embora indiretos, de que a competência social das crianças esteja relacionada com sua habilidade de identificar e de expressar emoções e de que a afetividade positiva esteja associada à popularidade (Fabes e colaboradores, 1999). Os autores que investigaram os atributos comportamentais correlatos a status sociométricos preocuparam-se com características de comportamento social, dando pouca atenção à expressão afetiva e emocional. Introduzimos neste estudo a investigação de características afetivas (alegria/tristeza, medo/coragem), com o objetivo de verificar em que medida sua aplicação na avaliação do outro está relacionada com competência social e com o gênero das crianças.

Diferenças de gênero foram constatadas em relação a popularidade/rejeição social (Hatzichristou \& Hopf, 1996), no relato de comportamentos pró-sociais como fatores de redução de dano em situações emocionais desconfortáveis (Rotenberg \& Eisenberg, 1997), na expressão de medo (Lewis \& Michalson, 1982) e na interpretação de indícios que revelam o estado emocional de outras pessoas (Lagattuta, Wellman \& Flavell, 1997). Meninas têm revelado consistentemente superioridade nesses atributos. Tendo em vista esses dados, podemos supor que haja diferença entre meninos e meninas no que diz respeito a preferência/rejeição social e nas descrições de atributos comportamentais relacionados a essas variáveis.

O número de escolhas mútuas positivas, incluído por Fukada, Fukada e Hicks (1997) para avaliação de status sociométrico, reflete, em certa medida, a reciprocidade nas interações e a consciência de ser apreciado pelos companheiros, pesquisada por MacDonald e Cohen (1995). Os últimos autores constataram que crianças rejeitadas demonstraram menor consciência de sua competência social do que as populares. Com base nesse estudo, podemos esperar que as escolhas mútuas preponderem no grupo de crianças socialmente preferidas.

Nossos principais objetivos com o presente estudo foram verificar em pré-escolares alguns atributos comportamentais correlatos de escolhas positivas/ negativas das crianças e a diferença entre os gêneros quanto à relação entre preferência/rejeição social e às características comportamentais associadas a essas 
medidas. Foram objetivos específicos complementares: (1) verificar as relações entre status sociométrico e características comportamentais segundo julgamento dos colegas; (2) analisar diferenças de gênero quanto a status social; (3) estabelecer as relações entre status social e gênero de um lado e atribuição de características comportamentais pelos colegas de outro; (4) verificar diferenças de status social e gênero quanto ao número de escolhas recíprocas.

\section{Método}

\section{Participantes}

Participaram do estudo 31 crianças - 18 meninos e 13 meninas - de uma classe de Pré-escola Municipal situada em bairro de classe média e média-baixa da Zona Sul da cidade de São Paulo - com cinco anos e sete meses de idade em média, variando de cinco anos e quatro meses até seis anos e três meses. As crianças participaram como sujeitos que podiam escolher e ser escolhidos.

\section{Procedimento}

$1^{a}$ etapa - Familiarização das crianças com a pesquisadora

Nesta etapa, a pesquisadora - após ser apresentada pela diretora como uma pessoa que estaria com as crianças por algum tempo, observando-as e fazendo algumas perguntas - passou duas horas em sala de aula, observando as atividades das crianças, que se sentavam distribuídas em grupos de três ou quatro em cada uma das nove mesas circulares da sala de aula. Passou de mesa em mesa perguntando o nome e idade de cada criança e aspectos de sua vida - onde moravam, como vinham para a escola, se tinham irmãos, etc. - e respondendo às perguntas que lhe eram feitas.

\section{$2^{a}$ etapa - Entrevistas}

Após a primeira etapa, a pesquisadora passou a chamar cada criança para a entrevista individual. As entrevistas foram realizadas em local privativo, fora do ambiente de sala de aula. Antes de iniciar as perguntas, a entrevistadora garantia às crianças que não comentaria suas respostas com ninguém e pedia que elas fizessem o mesmo. As entrevistas foram realizadas em seis dias da última quinzena de abril, tendo as aulas iniciado no dia 8 de fevereiro. Acreditamos, portanto, que já havia tempo suficiente para que as crianças se conhecessem, embora algumas tivessem tido maior contato entre si por terem freqüentado a mesma creche no ano anterior, ou por serem vizinhas, ou filhas de famílias amigas.

Avaliação de preferência e de rejeição social - A primeira pergunta feita à criança era: "qual o(a) colega de quem você mais gosta?" Em seguida, perguntava-se: "e depois deste(a), de quem você mais gosta?". Depois da segunda citação, a última pergunta era repetida, até que se obtivessem os três colegas de quem o(a) participante mais gostava. Perguntava-se, então: "agora, me diga qual o(a) colega de quem você menos gosta" e repetia-se o procedimento até se obterem as três escolhas negativas. As crianças, em geral, tiveram maior dificuldade em citar os colegas de quem menos gostavam. Alguns participantes citaram apenas um ou dois nomes de companheiros de que mais ou de que menos gostavam, declarando não haver mais nenhuma criança naquela condição. Nesses casos, foram computados apenas os colegas citados.

Determinação do status sociométrico - Após perguntar a cada criança individualmente quais os três colegas de quem mais e de quem menos gostava, computou-se o número de escolhas positivas e negativas que cada participante recebeu, obtendo-se duas medidas sociométricas derivadas: preferência social: gosta mais - (menos) gosta menos; e impacto social: gosta mais + (mais) gosta menos. Em seguida, os escores de preferência e de impacto social foram padronizados e as crianças foram classificadas em cinco grupos de status distintos, de acordo com os seguintes critérios: popular - escore padronizado de preferência social maior que 1,0; escore padronizado de gostar mais maior que 0; escore padronizado de gostar menos menor que 0 ; rejeitado - escore padronizado de preferência social menor que $-1,0$; escore padronizado de gostar menos maior que 0 ; escore padronizado de gostar mais menor que 0 ; negligenciado - escore padronizado de impacto social menor que $-1,0$; escore absoluto de gostar mais igual a 0 (esse grupo difere das crianças rejeitadas pelo baixo escore de gostar menos); controverso - escore padronizado de impacto social maior que 1,0; escores padronizados de gostar mais e de gostar menos maiores que 0 ; intermediário ou médio - escore padronizado de preferência social entre -0,5 e 0,5.

Avaliação de atributos comportamentais - Utilizou-se um instrumento, composto de sete pranchas com figuras de crianças que ilustravam características comportamentais diferentes. Cinco pranchas ilustravam atributos sociais e duas, atributos afetivos. Na Figura 2, está reproduzida uma das pranchas utilizadas, representando dois atributos comportamentais da esfera afetiva ("mostrar-se alegre/ triste"). Cada prancha foi dividida ao meio por uma linha vertical, obtendo-se duas colunas (uma à esquerda e outra à direita). Em cada uma das colunas havia ao menos um menino e uma menina demonstrando cada atributo comportamental. Um dos lados da prancha ilustrava uma característica de comportamento e o outro, sua oposta ou negativa. Quando se perguntava à criança a respeito 
de um atributo, cobria-se a outra metade da folha, que ilustrava seu inverso. Foram as seguintes as instruções para cada prancha (a primeira pergunta relativa a cada par descrito era ilustrada por figura situada ao lado esquerdo da prancha e a segunda era representada do lado direito): Prancha 1 - "Estas crianças têm muitos amigos". / "Estas crianças têm poucos amigos". Prancha 2 - "Estas crianças sorriem muito, estão quase sempre alegres". / "Estas crianças sorriem pouco, às vezes choram, estão quase sempre tristes". Prancha 3 - "Estas crianças são muito agarradas à professora, ficam muitas vezes junto dela". / "Estas crianças são pouco agarradas à professora". Prancha 4 - "Estas crianças são mandonas. Vivem dando ordens". / "Estas crianças são mandadas; quase sempre estão fazendo o que os outros mandam". Prancha 5 "Estas crianças quase nunca fazem as atividades". / "Estas crianças quase sempre fazem as atividades". Prancha 6 "Estas crianças brigam muito. São briguentas". / "Estas crianças quase nunca brigam". Prancha 7 - "Estas crianças são corajosas; não têm medo de quase nada". / "Estas crianças são medrosas; têm medo de muitas coisas". A ordem de apresentação das pranchas foi aleatória, com exceção da primeira ("tem muitos/ poucos amigos"), que foi propositadamente apresentada nessa posição por acreditarmos que ilustrava uma característica mais concreta e de mais fácil compreensão pelos participantes.

Após cada instrução, perguntava-se à criança: "Qual o seu ou a sua colega que mais se parece com estas
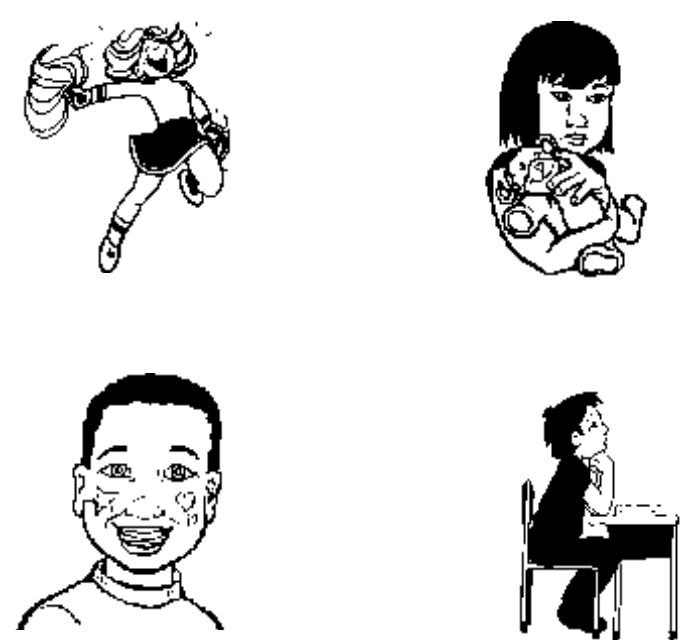

Estas crianças sorriem muito, estão quase sempre alegres.

Estas crianças sorriem pouco, às vezes choram, estão quase sempre tristes.

Figura 2 . Prancha que ilustra as características "alegre"/ "triste" crianças?" Quando essa instrução parecia não ser entendida, a entrevistadora repetia a descrição inicial, por exemplo: “Qual colega tem muitos amigos?". Para alguns participantes pareciam ser mais bem entendidas as perguntas: "Quem é como esta criança?" ou "Quem é assim?" Alguns sujeitos tiveram dificuldade em nomear crianças em certos atributos, enquanto outros imediatamente expuseram uma relação de dois, três, quatro e até cinco nomes. Nesses casos, computou-se apenas o primeiro nome da lista.

\section{Resultados}

\section{Atributos Comportamentais como Variáveis Preditivas de Preferência e de Rejeição Social}

A Tabela 1 mostra as correlações entre as avaliações de características comportamentais e os escores de escolhas positivas (de quem gosta mais) e negativas (de quem gosta menos). Foi utilizado o índice de correlação de Pearson. Como se observa pela Tabela 1, os principais correlatos dos escores de escolha positiva foram "mostrar-se alegre", "participar das atividades", "ter muitos amigos", "ser independente" e "brigar pouco", ou seja, todos os atributos positivos, com exceção de "mostrar-se corajoso", categoria que, como veremos adiante, correlacionou-se positivamente com as escolhas positivas apenas para as meninas. Os principais correlatos dos escores de escolhas negativas foram: "provocar brigas", "dar ordens", "mostrar-se medroso", "participar pouco das atividades" e "ter poucos amigos". Com exceção da característica "ser dependente", verificou-se correlação positiva entre os escores de escolha negativa e os atributos comportamentais negativos.

Pela coerência do padrão de correlações entre atributos comportamentais preditivos de preferência e de rejeição social, podemos depreender que o instrumento mostrou-se adequado para avaliar aquilo a que se propunha. As crianças, de maneira geral, compreenderam as perguntas, com exceção de "cumprir ordens", item com o qual procurávamos avaliar a característica submissão, mas que muitos participantes entenderam como "colabora" ou "procura agradar os outros".

Para se apurarem possíveis diferenças de gênero, os dados foram submetidos a Análises de Regressão, através da técnica Stepwise (Green, Salkind \& Akey, 2000), utilizando-se os 14 atributos comportamentais (dez da esfera social e quatro da esfera afetiva) como variáveis preditivas e as escolhas positivas / negativas como variáveis critério (Tabela 2). Verificamos pela Tabela 2 que, para os meninos, o modelo para as escolhas positivas 
Tabela 1. Correlações entre Atributos Comportamentais e Escores Brutos de Escolhas Positivas e Negativas.

\begin{tabular}{lcc}
\hline \multicolumn{1}{c}{\begin{tabular}{c} 
Atributos \\
\multicolumn{1}{c}{ Esfera social }
\end{tabular}} & Escolhas Positivas & Escolhas Negativas \\
\hline Tem muitos amigos & & 0,153 \\
Tem poucos amigos & $0,485^{* *}$ & $0,597^{* * *}$ \\
Provoca brigas & $-0,057$ & $0,689^{* * *}$ \\
Briga pouco & $-0,109$ & $-0,056$ \\
Independente da professora & $0,308^{*}$ & 0,259 \\
Dependente da professora & $0,345^{*}$ & 0,219 \\
Participa das atividades & $-0,193$ & $-0,205$ \\
Participa pouco das atividades & $0,511 * *$ & $0,4677^{* *}$ \\
Dá ordens & $-0,072$ & $0,513^{* *}$ \\
Cumpre ordens & $-0,133$ & 0,084 \\
& 0,194 & \\
Alegre $\quad$ Esfera afetiva & & $-0,094$ \\
Triste & $0,513^{* *}$ & $0,326^{*}$ \\
Corajoso & $-0,148$ & $-0,115$ \\
Medroso & 0,246 & $0,581^{* * *}$ \\
\hline
\end{tabular}

*** $p<0,001 ; * * p<0,01 ; * p<0,05$

inclui apenas o atributo "ter muitos amigos", que explica $24 \%$ da variância dos dados, enquanto para as meninas o modelo, que explica $71 \%$ da variância dos dados, inclui "mostrar-se alegre" (47\% da variância) e "corajoso" (24\% da variância). Quanto às escolhas negativas, para os meninos, o modelo inclui apenas a característica "provocar brigas", que explica $41 \%$ da variância. Para as meninas, explicam as escolhas negativas os atributos "provocar brigas" ( $47 \%$ da variância) e "mostrar-se triste" (17\% da variância), que, juntos, são responsáveis por $64 \%$ da variância dos dados.

\section{Análise em Função de Status Sociométrico}

Foi feita uma análise dos dados com base nas categorias de status sociométrico de Coie e colaboradores (1982).
Duas das 31 crianças não se enquadraram em nenhum grupo de status, segundo o critério dos autores. Das 29 crianças que puderam ser classificadas, sete $(24,1 \%)$ foram consideradas populares, sete $(24,1 \%)$ rejeitadas, quatro $(13,8 \%)$ negligenciadas, três $(10,3 \%)$ controversas e oito $(27,6 \%)$ médias.

\section{Efeitos de Gênero em Relação a Status Social}

Computou-se o status sociométrico em função de gênero. Testes de qui-quadrado foram realizados para verificar se houve escolha diferencial de meninos e meninas para cada grupo de status social. Constatou-se que as meninas $(85,7 \%)$ tenderam a ser mais escolhidas como populares do que os meninos $(14,3 \%), x^{2}(1)=3,571$;

Tabela 2. Análises de Regressão Prevendo Escolhas Positivas e Negativas em Função dos Atributos Comportamentais para cada Gênero

Escolhas Positivas

\begin{tabular}{llll|lllc}
\multicolumn{3}{c}{ Meninos } & \multicolumn{5}{c}{ Meninas } \\
\hline Atributos & $\mathrm{R}^{2+}$ & $F(1,16)$ & $\beta$ & Atributos & $R^{2+}$ & $F(1,11)$ & $\beta$ \\
\hline Muitos amigos & 0,239 & $6,348^{*}$ & 0,533 & Alegre & 0,474 & $11,810^{* *}$ & 0,736 \\
& & & & Corajoso & 0,717 & $16,233^{* * *}$ & 0,497 \\
\hline
\end{tabular}

Escolhas Negativas

Meninos

\begin{tabular}{llll|llll}
\hline \multicolumn{3}{c}{ Meninos } & \multicolumn{5}{c}{ Meninas } \\
\hline Atributos & $\mathrm{R}^{2+}$ & $\mathrm{F}(1,16)$ & $\beta$ & Atributos & $\mathrm{R}^{2+}$ & $\mathrm{F}(1,11)$ & $\beta$ \\
\hline Provoca brigas & 0,408 & $15,819^{* * *}$ & 0,705 & Provoca brigas & 0,474 & $11,824^{* *}$ & 0,586 \\
& & & & Triste & 0,646 & $11,955^{* *}$ & 0,453 \\
\hline
\end{tabular}

$\overline{* * *} p<0,001 ; * * p<0,01 ; * p<0,05 ;{ }^{+} \mathrm{R}^{2}$ ajustado 
$p<0,10$, e que foram menos escolhidas como negligenciadas $(0,0 \%)$ do que eles $(100 \%), x^{2}(1)=4,0$; $p<0,05$.

Encontrou-se um efeito multivariado significativo de gênero para o conjunto dos 14 atributos comportamentais, Roy $=8,062, \mathrm{~F}(14,7)=4,031 ; p<0,05$. Especificamente, as meninas foram mais citadas do que os meninos nos itens "dar ordens" $(M=1,88 \pm 0,31$ vs. $M=0,62 \pm 0,26)$ e "mostrar-se triste" $(M=1,13 \pm 0,20$ vs. $M=0,31 \pm 0,17)$.

\section{Efeitos do Status Sociométrico}

Encontrou-se um efeito principal multivariado significativo para status sociométrico, Roy $=8,240, F$ $(14,10)=5,886 ; p<0,01$. Efeitos principais correspondentes foram identificados em análises univariadas para três características comportamentais na esfera social - "provocar brigas", $F(4,20)=5,407$; $p<$ 0,01 , “dar ordens", $F(4,20)=6,737 ; p<0,001$, e "ter pouco amigos", $F(4,20)=2,856 ; p<0,05$, - e para duas características na esfera afetiva - "mostrar-se medroso", $F(4,20)=3,387 ; p<0,05$, e "mostrar-se triste", $F(4,20)$ $=7,296 ; p<0,01$. A Tabela 3 apresenta as médias e os erros padrão para essas características.
Comparações dois a dois através do critério de Bonferroni indicaram que o grupo popular superou todos os demais nesse aspecto, diferindo dos rejeitados, negligenciados, controversos e médios de forma significativa $(p<0,05)$.

\section{Efeitos de Interação entre Gênero e Status Sociométrico}

Encontrou-se um efeito multivariado significativo de interação entre gênero e status sociométrico, Roy $=7,192$, $F(14,9)=4,624 ; p<0,01$. Apenas uma interação univariada referente a "mostrar-se triste", $F(3,20)=4,816 ; p<0,01$, foi significativa, alterando o efeito principal de gênero descrito anteriormente. Para os meninos não se encontraram diferenças nessa categoria em função de status sociométrico, enquanto as meninas rejeitadas foram mais citadas como "tristes" que as populares.

\section{Distribuição das Atribuições Considerando o Gênero dos Participantes conforme sua Avaliação no Papel de Juízes}

Um teste t para avaliar efeito de gênero com relação ao número de escolhas recíprocas indicou que as meninas $(M=1,31 \pm 0,31)$ apresentaram mais escolhas mútuas que os meninos $(M=0,44 \pm 0,12), t(29)=2,612(p<$ $0,05)$. Em decorrência desse resultado, verificamos ser

Tabela 3. Média e Erro Padrão de Avaliações de Características Comportamentais em Função de Status Sociométrico

\begin{tabular}{lcccccccccr}
\hline Status sociométrico & \multicolumn{1}{c}{ Poucos amigos } & \multicolumn{4}{c}{ Provocar brigas } & \multicolumn{2}{c}{ Dar ordens } & \multicolumn{2}{c}{ Triste } & \multicolumn{2}{c}{ Medroso } \\
& $M$ & $E P$ & $M$ & $E P$ & $M$ & $E P$ & $M$ & $E P$ & $M$ & $E P$ \\
\hline Popular & 0,57 & 0,35 & 0,14 & 0,32 & 0,29 & 0,38 & 0,14 & 0,30 & 0,57 & 0,49 \\
Rejeitado & 1,00 & 0,35 & 1,00 & 0,32 & 0,57 & 0,38 & 1,29 & 0,30 & 0,57 & 0,49 \\
Negligenciado & 0,75 & 0,47 & 0,25 & 0,43 & 0,50 & 0,50 & 0,25 & 0,40 & 0,25 & 0,65 \\
Controverso & 2,67 & 0,54 & 3,00 & 0,49 & 3,00 & 0,58 & 0.67 & 0,46 & 3,67 & 0,75 \\
Médio & 0,38 & 0,33 & 0,50 & 0,30 & 0,50 & 0,35 & 0,25 & 0,28 & 0,25 & 0,46 \\
\hline
\end{tabular}

Comparações dois a dois através do critério de Bonferroni revelaram que, em relação a "provocar brigas", a "dar ordens" e a "mostrar-se medroso", as crianças controversas tiveram escores significativamente maiores $(p<0,05)$ que as populares, as rejeitadas, as negligenciadas e as médias. As controversas foram mais freqüentemente citadas como tendo "poucos amigos" em comparação com as populares e com as médias. No que se refere a "mostrar-se triste", as rejeitadas receberam escores significativamente superiores $(\phi<0,05)$ aos das populares e das médias.

Através de um teste de análise de variância univariado (ANOVA), constatou-se também um efeito principal significativo de status sociométrico sobre o número de escolhas mútuas, $F(4,24)=10,941 ; p<0,001$. necessário ter a cautela de separar, para depois relacionar, o gênero de quem atribuiu e o de quem recebeu as escolhas, pois é possível que a atribuição mais freqüente de certas características a meninos ou meninas tenha-se devido ao gênero da criança que os julgou. Os resultados descritos anteriormente referem-se à análise dos dados das crianças que foram escolhidas, ou seja, dos participantes na qualidade de julgados. Lembremo-nos, contudo, de que os participantes puderam ser escolhidos, mas também escolheram, ou seja, também foram juízes. Para melhor compreender a questão de gênero em conexão com a descrição de características comportamentais, é necessário que analisemos não só o gênero de quem foi escolhido, mas também o de quem escolheu. Procedendo a essa análise através de testes t, 
constatamos que os meninos atribuíram escolhas positivas (gostar mais) predominantemente a meninos $(t(29)=$ $2,955 ; p<0,01)$ e que as meninas fizeram mais escolhas positivas de meninas $(t(29)=3,247 ; p<0,01)$.
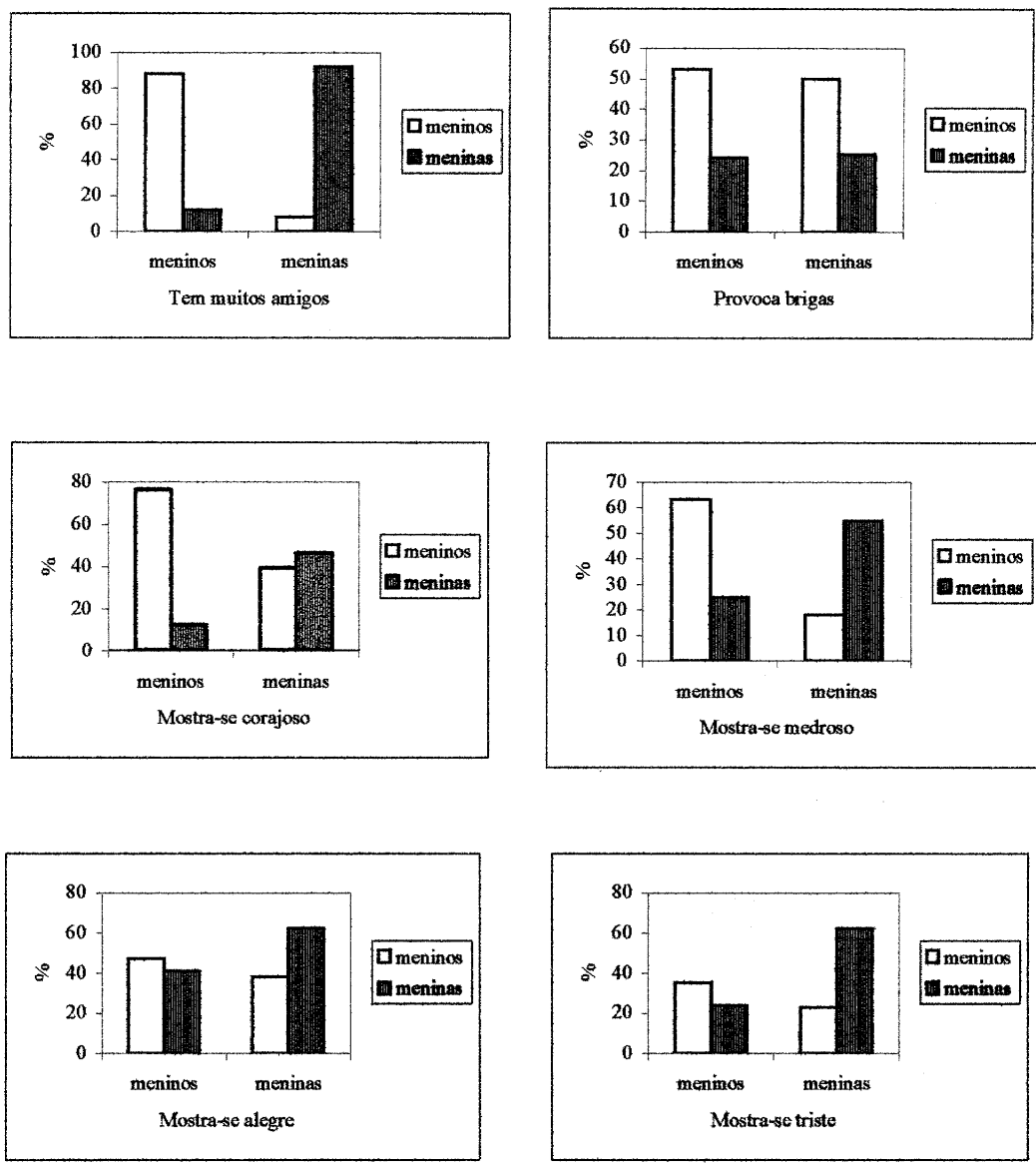

Figura 3. Porcentagens de escolhas de meninos e meninas em relação ao gênero de quem foi julgado como portador de diferentes atributos comportamentais. Nas abscissas, estão os juízes e nas colunas, as porcentagens de julgados

Com referência às descrições comportamentais, apresentamos na Figura 3 os atributos que mais se destacaram nas análises precedentes. Constatamos que meninas e meninos atribuem predominantemente a crianças do mesmo gênero a característica "ter muitos amigos" $\left(x^{2}=18,295 ; \mathrm{p}<0,001\right)$, tendendo também a atribuir a elas as características "mostrar-se corajoso" $\left(x^{2}\right.$ $=5,113 ; p<0,10)$, "medroso" $\left(x^{2}=5,185 ; p<0,10\right)$, "alegre" ( $x^{2}=2,266$; não significativo) e "triste" ( $x^{2}=$ $4,661 ; p<0,10)$. Ambos os gêneros descrevem os meninos como "briguentos" $\left(x^{2}=0,024\right.$; não significativo).

\section{Discussão}

Para a clareza da discussão e para podermos comparar nossos dados aos da literatura, explicitaremos inicialmente o que pretendemos avaliar com as categorias comportamentais enfocadas no presente estudo. "Provocar brigas" tem sido, ao lado de "bater", um dos principais comportamentos empregados para denotar agressividade, assim como "ter muitos amigos" e "quase
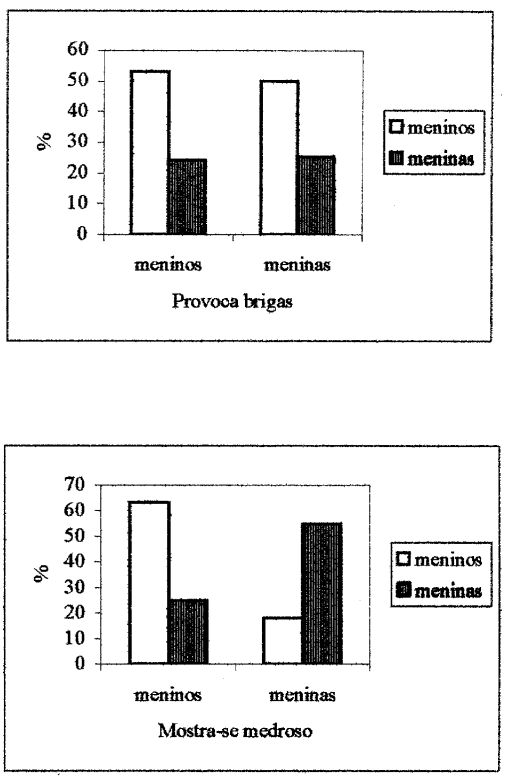

não ter amigos" são indicadores de aceitação e de isolamento social, respectivamente (Hatzichristou \& Hopf, 1996; Underwood, 1997). Ao escolhermos as variáveis "dar ordens" e "cumprir ordens", tivemos o propósito de comparar as características de dominação e de submissão. A nomenclatura utilizada para as demais características é mais descritiva. Para a avaliação da expressão de sentimentos, utilizamos alegria/tristeza e coragem/medo; para a caracterização da relação com a professora, dependência/ independência; e para a descrição do envolvimento nas atividades, participação/ não-participação.

\section{Preferência, Rejeição Social e Avaliação de Características Comportamentais}

Este trabalho possibilitou constatar que crianças de cinco anos já discriminam adequadamente as características 
comportamentais dos companheiros, nos domínios social e afetivo. Podemos estabelecer paralelos com alguns estudos de desenvolvimento, que relatam que crianças de cinco a seis anos são mais capazes do que as de três e quatro anos de perceber processos mentais e eventos que precedem as emoções (Lagattuta e colaboradores, 1997; Laible \& Thompson, 1998). Analisando-se os correlatos de escolhas positivas e negativas, constatamos que as crianças associaram a maioria das características comportamentais positivas (aceitação social, participação nas atividades, alegria, independência e não-agressividade) aos companheiros escolhidos como mais queridos, enquanto os menos queridos receberam maior número de atribuições negativas (pouca participação, isolamento, mostrar-se agressivo, dominador e medroso). A associação de características socialmente apreciadas aos escores de preferência social é esperada, uma vez que as crianças já assimilaram muitas das representações coletivas do que é valorizado culturalmente (Morais, 1980; Morais \& Carvalho, 1994; Nicolopoulou \& Weintraub, 1998).

No que diz respeito aos correlatos de escolhas negativas e positivas na esfera social, a maior parte de nossos dados são coerentes com os relatados na literatura. Diversos estudos demonstram que agressividade e isolamento social são fatores relacionados à rejeição por parte de companheiros (Bussab \& Maluf, 1998; Hatzichristou \& Hopf, 1996; Underwood, 1997). No trabalho de Coie e colaboradores (1982), a dependência ("pedir ajuda") associou-se à rejeição social e, no estudo de Vosk e colaboradores (1982), a falta de participação nas atividades caracterizou crianças impopulares. Verschueren e Marcoen (1999) usaram o ajustamento escolar (critério semelhante ao de participação nas atividades) como um dos indicadores de competência socioemocional. Esperávamos que a submissão fosse uma característica associada às escolhas negativas. Observamos, entretanto, que as instruções da prancha que procurava avaliar submissão foram entendidas por alguns participantes como "ser colaborador" e não como "ser submisso" conforme intencionávamos, e que a característica oposta "ser dominador" foi a que apresentou correlação com as escolhas negativas.

Ao procedermos à análise de regressão dos fatores preditivos de preferência e de rejeição social, encontramos, entretanto, importantes diferenças de gênero referentes aos atributos que predizem escolhas positivas e negativas. Enquanto a principal característica preditiva para escolhas positivas nos meninos foi aceitação social, as meninas preferidas foram descritas como alegres e corajosas A agressividade para ambos os gêneros e a tristeza para as meninas foram atributos preditivos para escolhas negativas. Embora haja muitos trabalhos que demonstram que isolamento social e agressividade correlacionam-se negativamente e que independência relaciona-se positivamente com popularidade (Hatzchristou \& Hopf, 1996; Parke e colaboradores, 1997; Stormshak, Bierman, Bruschi, Dodge \& Coie, 1999), as variáveis afetivas, especialmente "demonstrar medo/ coragem", foram menos exploradas nos estudos de competência social. Hartup (1975) relata que a coragem é uma das qualidades positivas que adolescentes consideram importantes nos amigos. É interessante observar que as crianças pequenas que constituíram a amostra do presente estudo já diferenciam essa característica e a associam a seus colegas favoritos. Stocker e Dunn (1990) verificaram que crianças que manifestam mais emoções negativas experimentam maior rejeição por parte de companheiros. Evidentemente, é mais agradável estar perto de pessoas alegres do que de pessoas tristes e agressivas (Hubbard \& Coie, 1994).

De maneira geral, a literatura indica maior manifestação de emoções e maior sensibilidade às expressões emocionais por parte das meninas. Rotenberg e Eisenberg (1997) encontraram diferenças de gênero relativas à maior busca de informações a respeito de uma situação geradora de impacto emocional e à demonstração mais freqüente de reações pró-sociais a essas situações por parte das meninas. Esses autores descrevem ainda diferenças na inibição de emoções, conjeturando que os meninos sofrem mais pressões para inibir a expressão de emoções do que as meninas. Lagattuta e colaboradores (1997) constataram que as meninas superaram os meninos na interpretação de indícios cognitivos preditivos de emoções. Lewis e Michalson (1982), num estudo observacional sobre variadas situações evocadoras de emoção, verificaram que as meninas mostravam expressões mais intensas de medo. Embora não tenham ligação direta com nossos dados, os resultados desses estudos levam-nos a supor, por um lado, maior sensibilidade das meninas para características afetivas dos parceiros de interação e, por outro, a conjeturar sobre a valorização da expressão emocional no gênero feminino. Esperávamos que os atributos medo/coragem fossem mais apreciados nos meninos, uma vez que é essa uma dimensão mais valorizada e socialmente esperada para o gênero masculino. Contudo, os dados comentados adiante no tópico em que se consideram os dois gêneros no papel de juízes, trazem maiores esclarecimentos sobre a valorização do predicado "coragem". Lembremos que estudamos crianças de classe média-baixa e média, que possuem valores tradicionais e conservadores. Entretanto, para que possamos tirar 
maiores conclusões a esse respeito, são necessários estudos comparativos que façam a avaliação cuidadosa da relatividade de valores culturais em segmentos populacionais.

\section{Status Sociométrico, Gênero e Atribuição de Características Comportamentais}

Através da análise de variância, constatamos que as meninas foram classificadas como mais populares e menos negligenciadas do que os meninos. Coie e colaboradores (1982) encontraram fenômeno semelhante na amostra que estudaram. Em seu estudo, os meninos foram mais selecionados como rejeitados do que as meninas, o que confirma os achados de outras pesquisas que indicam que os meninos encontram mais dificuldade nas relações com os companheiros do que as meninas (Hatzichristou \& Hopf, 1996; Parke e colaboradores, 1997). Os dados relativos à escolha mútua - que revelaram que as meninas superaram os meninos neste aspecto - são compatíveis com a maior facilidade de integração social no gênero feminino: indubitavelmente, há maior facilidade na interação quando existe reciprocidade e correspondência de afetos. Ainda no que diz respeito às escolhas mútuas e coerentemente com a hipótese de que as crianças populares são mais conscientes de sua própria competência social (MacDonald \& Cohen, 1995), as crianças do grupo popular apresentaram maior reciprocidade nas escolhas mútuas positivas que os demais grupos.

No que se refere à avaliação de características comportamentais, a análise de variância revelou que o grupo que mais se destacou dos demais foi o de crianças controversas, que foram avaliadas como mais agressivas, mais dominadoras e mais medrosas do que as demais, inclusive do que as rejeitadas, e mais isoladas do que as populares e médias. A maior parte dos estudos relata que as crianças rejeitadas partilham essas características com as controversas, que, entretanto, também demonstram algumas características pró-sociais apresentadas pelas populares (Coie e colaboradores, 1982; Hatzichristou \& Hopf, 1996; Parke e colaboradores, 1997; Stormshak e colaboradores, 1999). Não encontramos esse efeito no presente estudo, provavelmente devido ao pequeno número de crianças controversas. A única característica significativamente associada ao grupo de crianças rejeitadas foi a tristeza, dado que é consistente com estudos que avaliam competência social em relação a controle emocional e que indicam que a afetividade positiva correlaciona-se com status social elevado (Fabes e colaboradores, 1999). Ao analisarmos os efeitos de interação entre gênero e status sociométrico, constatamos que a característica afetiva "tristeza", alterando o efeito principal de gênero, revelou impacto significativo no julgamento das meninas rejeitadas.

Observamos maior número de escolhas positivas recíprocas entre as meninas, fato que pode estar relacionado com as características predominantemente femininas de se dedicarem a atividades que permitem maior intimidade e em que a percepção interpessoal prepondera sobre a ação, enquanto a atuação dos meninos é mais marcada pelo movimento e pelo conflito. Tais fenômenos se revelam nas atividades simbólicas, como em brincadeiras imaginativas e em narrativas (Morais, 1980; Morais \& Carvalho, 1994; Nicolopoulou \& Weintrab, 1998). Entretanto, o maior número de escolhas mútuas entre as meninas alerta-nos para a possibilidade de que tenha havido, em relação às descrições comportamentais, ao lado do efeito do gênero de quem foi escolhido, aquele de quem fez a escolha. Portanto, para interpretarmos adequadamente os dados, achamos necessário considerar os participantes sob dois ângulos: 1) do ponto de vista de quem fez a escolha, considerandose os participantes como juízes e 2) sob o prisma de quem foi escolhido, considerando-se as crianças como alvos de julgamento. Mantendo-se em perspectiva essa dupla condição dos sujeitos, podemos indagar: o maior número de escolhas recíprocas entre as meninas faria com que elas fossem as principais responsáveis pelas descrições comportamentais do grupo de mesmo gênero? Ao julgarem as colegas, elas valorizariam mais suas características afetivas? Ou nos meninos seriam mais notados os atributos comportamentais com maior visibilidade, ao passo que nas meninas seriam mais valorizadas as características de afetividade? Como não foi possível responder a essas questões de forma direta, procuramos analisar separadamente o gênero dos participantes na qualidade de juízes e de julgados para procurarmos algumas respostas a essas questões.

\section{Os Dois Ângulos da Escolha: Gênero das Crianças como Juízes e como Alvos de Julgamento}

Verificamos que houve maior número de escolhas positivas entre crianças do mesmo gênero, dado que é coerente com as constatações de segregação por sexo em brincadeira livre de pré-escolares (La Frenière, Strayer \& Gauthier, 1984; Morais, 1980; Otta \& Sarra, 1990), de maior atração mútua entre pessoas que partilham atitudes e interesses semelhantes e, conseqüentemente, consistente com a tendência de se escolherem predominantemente pessoas do mesmo gênero como amigas (Furnham, 1989; Sippola, Bukowski \& Noll, 1997). Dentre as características que se mostraram relevantes nas análises estatísticas, a única 
preponderantemente atribuída a um dos gêneros foi a agressividade, considerada por meninos e meninas como um atributo masculino. Stormshak e colaboradores (1999), estudando crianças em idade escolar, verificaram que as diferenças de gênero em relação à aceitação por parte de companheiros agressivos variam em função do nível de agressividade tolerada pelo grupo, constatando ser essa uma característica menos definidora de rejeição social para as meninas. Nossos dados contrariam esses achados, mas confirmam em parte os resultados de Coie e colaboradores (1982) que verificaram que, em crianças de nove a 11 anos, os meninos foram mais freqüentemente citados no item "provoca brigas" do que as meninas.

No que diz respeito à aceitação social, foi altamente consistente a atribuição dessa característica a crianças de mesmo gênero. Como há uma aproximação maior entre crianças de mesmo gênero, elas, provavelmente, tendem a prestar mais atenção umas às outras e a ter melhor percepção umas das outras. Essa tendência se replica em maior ou menor grau para as características afetivas: alegria/tristeza e coragem/medo. Dessa forma, não podemos descartar a suposição de que as características afetivas atribuídas preponderantemente às meninas especialmente a tristeza, e, em menor grau, o medo e a alegria - devam ser consideradas mantendo-se em perspectiva o duplo papel das crianças nas escolhas: como juízes e como alvos de julgamento. Quanto ao predicado "coragem", os meninos atribuíram-no consistentemente a outros meninos, confirmando nossa suposição de que essa é uma característica preponderantemente masculina, pelo menos do ponto de vista dos meninos, já que as meninas conferiram-na aos dois gêneros. Há certamente carência de estudos que estabeleçam relações entre características afetivas e status sociométrico, e, mais ainda, de pesquisas que investiguem a relação entre gênero e características das crianças no papel de juízes. Serão necessários estudos posteriores, especialmente planejados para explorar essa questão, para que possamos obter respostas para algumas de nossas indagações, uma vez que o delineamento do presente trabalho apenas sinalizounos a importância de se diferenciarem os papéis dos participantes como juízes e como julgados na análise da atribuição de predicados comportamentais aos companheiros.

\section{Conclusão e Sugestões para Próximos Estudos}

Os resultados deste trabalho apontam-nos caminhos interessantes para futuras pesquisas e até para intervenções na área de competência social. Nossas principais contribuições disseram respeito à investigação de correlatos comportamentais de preferência/ rejeição social em crianças em idade pré-escolar e à inclusão da dimensão afetiva na caracterização de comportamentos associados a escolhas sociométricas positivas e negativas. Tomando-se como verdadeiro o modelo de Furnham (1989), apresentado na Figura 1, sobre as conseqüências da falta de competência social para o desenvolvimento de transtornos de conduta, evidencia-se a importância de se investigarem os aspectos emocionais relacionados com inabilidade social.

Quanto a futuros estudos, acreditamos serem interessantes algumas alterações no rol de características comportamentais pesquisadas. O presente trabalho mostrou a conveniência de inclusão do atributo "colabora com os companheiros" e de se modificarem as instruções da prancha que pretendia descrever comportamento submisso. Como a dimensão afetiva revelou-se tão importante para a avaliação de atributos associados à popularidade/rejeição para as meninas, seria interessante incluir no procedimento a pesquisa de outras características afetivas como a raiva e a vergonha, por exemplo, ou elaborar um instrumento com o objetivo exclusivo de avaliar o impacto da dimensão afetiva sobre as escolhas sociométricas. Nesse mesmo sentido, seria importante também a investigação, através de observações diretas do comportamento das crianças, das relações entre a manifestação de emoções e a dimensão preferência/rejeição social. Um estudo planejado para melhor diferenciar os participantes nos papéis de juiz e de alvo de julgamento também é necessário para se analisarem mais adequadamente os efeitos de gênero sobre a avaliação das crianças.

Evidentemente, são muito importantes estudos longitudinais que acompanhem as crianças no decorrer de seu desenvolvimento, procurando investigar as transformações que ocorrem com a idade e com a mudança de grupo de referência, assim como trabalhos que busquem intervir no grupo e nas crianças, com o objetivo de diminuir os efeitos da rejeição e do isolamento social. Uma vez que há um grande número de pesquisas focalizando as crianças rejeitadas e isoladas, são necessários estudos com amostras maiores de pré-escolares para a melhor compreensão das características e prognóstico das crianças controversas, menos estudadas até o presente.

Finalmente, evidencia-se também a necessidade de estudos comparativos que levem em conta a influência da cultura e da subcultura sobre a avaliação de características comportamentais por parte das crianças. Como exemplo, podem-se considerar, entre outros, os efeitos da valorização, negação ou repressão das manifestações de agressividade, da sujeição às normas 
sociais, da expressão e controle de sentimentos, como raiva, alegria/tristeza, ou medo/coragem em diferentes segmentos populacionais. Indubitavelmente, maiores conhecimentos na área contribuirão para o diagnóstico precoce e para a eficácia de procedimentos de intervenção que diminuam os riscos que a falta de competência social acarreta. Fogel (2000), comentando a visão de desenvolvimento como construção mediada culturalmente, considera o Brasil - por suas características peculiares de freqüentes mudanças nos sistemas político e econômico e, acrescentamos, por sua diversidade de subculturas - um campo especialmente profícuo para a investigação " $\mathrm{da}$ flexibilidade, da criatividade, da emergência e da manutenção de quasi-estabilidade em meio ao caos" (p. 318).

\section{Referências}

Attili, G. (1990). Successful and disconfirmed children in the peer group: Indices of social competence within an evolutionary perspective. Human Development, 33, 238-249.

Bretherton, I. \& Ridgeway, D. (1990). Assessing internal working models of the attachment relationship: An attachment story completion task for 3-years-old. Em: M. T. Greenberg, D. Ciccheti, \& E. M. Cummings (Orgs.), Attachment in the preschool years: Theory, research and intervention (pp. 87-119). Chicago: The University of Chicago Press.

Bussab, V. S. R. \& Maluf, M. P. C. (1998). A creche como contexto sócioafetivo de desenvolvimento: Os padrões interacionais e o ajustamento das crianças. Revista Brasileira de Crescimento e Desenvolvimento Humano, 8, 33-39.

Coie, J. D., Dodge, K.A. \& Coppotelli, H. (1982). Dimensions and types of social status: A cross-age perspective. Developmental Psychology,18, 557570.

Daniels, D.H. (1998). Age differences in concepts of self-esteem. MerrillPalmer Quarterly, 44, 234-258.

Fabes, R. A., Eisengerg, N., Jones, S., Smith, M., Guthrie, I., Poulin, R., Shepard, S. \& Friedman, J. (1999). Regulation, emotionality, and preschoolers' socially competent peer interaction. Child Development, $70,432-442$.

Fogel, A. (2000). O contexto sociocultural e histórico dos estudos do desenvolvimento. Psicologia: Reflexão e Crítica, 13, 311-318.

Fukada, H., Fukada, S. \& Hicks, J. (1997). The relationship between leadership and sociometric status among preschool children. The Journal of Genetic Psychology, 158, 481-486.

Furnham, A. (1989). Friendship and personal development. Em R. Porter \& S. Tomaselli (Org.), The dialectics of friendship (pp. 92-110). London: Routledge.

Green, S. B., Salkind, N.J. \& Akey, T. M. (2000). Using SPSS for Windows: Analyzing and understanding data. New York: Prentice Hall.

Hartup, W.W. (1975). The origins of friendships. Em M. Lewis \& L. Rosenblum (Org.) Friendship and peer relations (pp. 11-26). New York: John Wiley \& Sons.

Harter, S. \& Pike, R. (1984). The pictorial scale of perceived competence and social acceptance for young children. Child Development, 55, 1969 $-1982$.

Hatzichristou, C. \& Hopf. D. (1996). A multiperspective comparison of peer sociometric status groups in childhood and adolescence. Child Development, 67, 1085-1102.
Hubbard, J. A. \& Coie J. D. (1994). Emotional correlates of social competence in children's peer relationships. Merril-Palmer Quarterly, 40, 1 20.

La Frenière, P., Strayer, F.F. \& Gauthier, R. (1984). The emergence of same-sex affiliative preferences among preschool peers: A developmental/ethological perspective. Child Development, 55, 19581965.

Lagattuta, K.H., Wellman, H.M. \& Flavell, J.H. (1997). Preschoolers' understanding of the link between thinking and feeling: Cognitive cuing and emotional change. Child Development, 68, 1081-1104.

Laible, D. J. \& Thompson, R. A. (1998). Attachment and emotional understanding in preschool children. Developmental Psychology, 34, 1038 1045.

Leslie, A. M. (1991). The theory of mind impairment in autism: Evidence for a modular mechanism of development? Em A. Writen (Org.), Natural theories of mind: evolution, development and simulation of everyday mindreading (pp. 63-78). Oxford: Basil Blackwell.

Lewis, M. \& Michalson, L. (1982). The measurement of emotional state. Em C. E. Izard (Org), Measuring emotions in infants and children (pp. 178207). Cambribge: Cambridge University Press.

MacDonald, C.D. \& Cohen, R. (1995). Children awareness of which peers like them and which peers dislike them. Social Development, 4,182-193.

Morais, M. L. S. (1980). O faz-de-conta e a realidade social da criança. Dissertação de Mestrado não publicada, Programa de Pós-Graduação em Psicologia Experimental, Universidade de São Paulo, São Paulo, SP.

Morais, M. L. S. \& Carvalho, A.M.A.C. (1994). Faz-de-conta: Temas, papéis e regras na brincadeira de crianças de quatro anos. Boletim de Psicologia, 100/101, 21-30.

Nicolopoulou, A. \& Weintraub, J.W. (1998). Individual and collective representations in social context: A modest contribution to resuming the interrupted project of a sociocultural development psychology. Human Development, 41, 215-235.

Oppenheim, D. (1990). Assessing the validity of a doll play interview for measuring attachment in preschoolers. Tese de Doutorado não publicada. Department of Psychology, The University of Utah, Salt Lake City, Utah, Estados Unidos da América.

Otta E. \& Sarra, S. (1990). Um estudo sobre o sorriso e o riso em crianças de quatro a cinco anos. Psicologia - USP , 1, 13-24.

Parke, R. D., O' Neil, R., Spitzer, S., Isley, S., Welsh, M., Wang, S., Lee, J., Strand. C. \& Cupp, R. (1997). A longitudinal assessment of sociometric stability and the behavioral correlates of children's social acceptance. Merrill-Palmer Quarterly, 43, 635-662.

Rosen, C.S., Schwebel, D.C. \& Singer, J.L. (1997). Preschoolers' attributions of mental states in pretense. Child Development, 68, 1133-1142.

Rotenberg, K. J. \& Eisenberg, N. (1997). Developmental differences in the understanding of and reaction to others' inhibition of emotional expression. Developmental Psychology, 33, 526-537.

Rubin, K. H. (1990). Peer relationships and social skills in childhood - An international perspective: Introduction. Human Development, 33, 221 224.

Sippola, L. K., Bukowski, W. M. \& Noll, R. B. (1997). Dimensions of liking and disliking underlying the same-sex preference in childhood and early adolescence. Merril-Palmer Quarterly, 43, 591-609.

Stocker, C. \& Dunn, J. (1990) Sibling relationships in childhood: Links with friendships and peer relationships. British Journal of Developmental Psychology, 8, 227-244.

Stormshak, E. A, Bierman, K.L., Bruschi, C., Dodge, K.A \& Coie, J.D. (1999). The relation between behavior problems and peer preference in different classroom contexts. Child Development, 70, 169-182.

Underwood, M. K. (1997). Peer social status and children's understanding of the expression and control of positive and negative emotions. Merril-Palmer Quarterly, 43, 610-634.

Verschueren, K. \& Marcoen, A . (1999). Representation of self and socioemotional competence in kindergartners: Differential and combined effects of attachment to mother and to father. Child Development, $70_{2}$ 183-201. 
Vosk, B., Forehand, R., Parker, J. B. \& Rickard, K. (1982). A multimethod comparison of popular and unpopular children. Developmental Psychology, 18, 571-575.
Recebido em 18/07/2000

Revisado em 18/09/2000

Aceito em 18/09/2000

Sobre as autoras:

Maria de Lima Salum e Morais - Psicóloga formada pelo IPUSP, com atuação nas áreas de Educação e Saúde Pública, Mestre e Doutoranda em Psicologia Experimental pelo Instituto de Psicologia da Universidade de São Paulo.

Emma Otta - Psicóloga formada pelo IPUSP, com atuação na área de Etologia. Professora associada, livre-docente, Coordenadora do Programa de Pós-Graduação em Psicologia Experimental e Chefe do Departamento de Psicologia Experimental do Instituto Psicologia da Universidade de São Paulo.

Cristiana Tieppo Scala - Psicóloga formada pela PUCSP, com atuação na área de Psicologia do Esporte. Mestre e Doutoranda em Psicologia Experimental pelo Instituto de Psicologia da Universidade de São Paulo. 